\title{
Declines in dietary macronutrient intake in persons with HIV infection who develop depression
}

\author{
Rita Isaac ${ }^{1}$, Denise Jacobson ${ }^{1}$, Christine Wanke ${ }^{1}$, Kristy Hendricks ${ }^{1}$, Tamsin A Knox ${ }^{1,2}$ \\ and Ira B Wilson ${ }^{3, *}$ \\ ${ }^{1}$ Nutrition/Infection Unit, Department of Public Health and Family Medicine, Tufts University School of Medicine, \\ Boston, MA, USA: ${ }^{2}$ Division of Gastroenterology, Tufts-New England Medical Center, Boston, MA, USA: \\ ${ }^{3}$ Institute for Clinical Research and Health Policy Studies, Tufts-New England Medical Center, 750 Washington \\ Street \#345, Boston, MA 02111 , USA
}

Submitted 2 May 2006: Accepted 19 January 2007: First published online 21 June 2007

\begin{abstract}
Background: The effect of depression on dietary intake has not, to our knowledge, been examined in persons with HIV infection.

Methods: We conducted a longitudinal analysis of participants in the Nutrition for Healthy Living Study (NFHL). We measured changes in dietary macronutrient intake in participants who developed depression and, using multiple regression analysis, compared the changes with a control group of patients who did not become depressed.

Results: Ninety patients developed depression during the observation period, and we compared these with 152 non-depressed controls. The two groups had similar age and body mass index (BMI) at baseline, but those who developed depression were more likely to be female, less educated and had lower incomes. After adjustment, compared with non-depressed participants, those who developed depression had significantly greater decreases in the following daily intakes: total energy $(-341 \mathrm{kcal}, P=0.006)$, protein $(-12.3 \mathrm{~g}, P=0.02)$, total fat $(-18.5 \mathrm{~g}$, $P=0.008)$, carbohydrate $(-36.8 \mathrm{~g}, P=0.02)$, total fibre $(-4.3 \mathrm{~g}, P=0.001)$ and saturated fat $(-6.7 \mathrm{~g}, P=0.01)$. There were no significant differences in the daily intakes of simple sugars and long-chain $n-3$ fatty acids, or BMI.

Conclusion: Depression is associated with decreases in total daily energy intake and in six of the eight dietary components we measured. Clinicians should be aware that depression-associated nutritional deficiencies may complicate the care of persons with HIV.
\end{abstract}

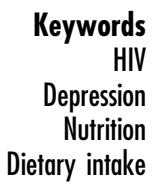

Malnutrition and weight loss continue to coexist with HIV disease in resource-adequate countries, despite the wide use of highly active antiretroviral therapy (HAART). The severity of weight loss has diminished compared with the pre-HAART era, but the incidence of weight loss has $\operatorname{not}^{1-3}$. The causes of persisting weight loss and malnutrition in HIV-infected individuals are multifactorial, with decreased energy intake due to anorexia and nausea related to HIV-associated illness or medications, increased energy demands related to chronic infection, HAART use, trouble swallowing/other oral problems and malabsorption/other gastrointestinal disorders all playing a role ${ }^{4-9}$.

Another potential contributor to HIV-related nutritional problems is depression. Estimates of the prevalence of depression in HIV-infected persons vary widely from 5 to $20 \%$, depending on the population studied, stage of HIV infection, the prevalence of other complicating conditions such as substance abuse and the assessment method ${ }^{10}$.
Poor appetite and weight loss are listed as the major diagnostic features of depression in the Diagnostic and Statistical Manual of Mental Disorders (DSM), 4th edition. Although depression may interfere with the quantity and quality of dietary intake, to our knowledge there is no published research that examines the relationship between depression and dietary macronutrient intake in persons with HIV. Furthermore, only a few studies in the broader literature have examined associations between depression and dietary intake. A cross-sectional study of 29 depressed subjects and a matched group of nondepressed subjects found that depressed subjects consumed a diet of poorer quality, with more carbohydrates and less protein, than subjects who were not depressed. The increase in carbohydrate consumption primarily came from an increase in sucrose (simple carbohydrate) intake ${ }^{11}$. With regard to micronutrients, two studies found an association between depression and low intake or serum levels of $n-3$ fatty acids ${ }^{12,13}$ and several studies 
have found an association between depression and folate and vitamin $\mathrm{B}_{12}$ deficiency ${ }^{14-17}$.

We therefore conducted a longitudinal analysis using data from a cohort study of persons with HIV, the Nutrition for Healthy Living Study (NFHL), to examine the relationship between depression and changes in dietary macronutrient intake. To strengthen our ability to draw causal inferences, we studied the diets of patients who screened negative for depression at two consecutive 6-month study visits, and then screened positive for depression at the next two study visits. We compared these patients with a control group of study patients who screened negative for depression at all four visits. We had one main study question: how does dietary macronutrient intake change in those who develop depression compared with those without depression? To our knowledge this is one of the first studies to focus on the impact of depression on dietary intake in an HIV-infected population.

\section{Methods}

\section{Participants}

The sample for this analysis of depression and diet was drawn from the NFHL cohort. NFHL is an observational cohort study of nutritional problems in HIV-infected adults, with sites in Boston, Massachusetts and Providence, Rhode Island, followed for 10 years from 1995 to May 2005. Patients aged 18 years or older at all stages of HIV disease, irrespective of their antiretroviral use, were eligible for NFHL, and special efforts were made to enrol women and minorities. Participants were recruited through advertisements in local newspapers, radio, health clinics and physician networks in Boston and Providence. Those with pregnancy, severe diarrhoea, thyroid disease, malignancies other than Kaposi's sarcoma or poor English language fluency at the time of recruitment were excluded. The following data were collected at a baseline clinic visit and at semi-annual follow-up visits: sociodemographics, weight, height, anthropometric measurements, dietary intake, clinical status, symptoms of depression, CD4 cell count, HIV viral load, and use of HIV-related medications and other medications. The NFHL study enrolled a total of 881 participants during the 10-year study period. All protocols and procedures of the study were reviewed and approved by the Institutional Review Board at each institution.

\section{Variables}

\section{Depression}

Depression was measured in NFHL by an intervieweradministered eight-item screening questionnaire developed by Burnam et al. ${ }^{18}$. This screener was developed for use in the Medical Outcomes Study ${ }^{19}$, and includes six items from the Center for Epidemiological Studies Depression Scale (CES-D) ${ }^{20-23}$ and two from the Diagnostic Interview Schedule ${ }^{24,25}$ (see Appendix for items). It has been used in a wide variety of studies ${ }^{26-32}$. Burnam et al. developed a weighted scoring strategy to maximise the prediction of depressive disorder, as defined in the 3rd edition of the DSM (DSM-III), from these eight items. To classify participants as depressed, we used the cut-off recommended in the original paper of $0.06^{18}$. This cut-off is interpreted as the probability, estimated from the prediction equation, that an individual has a DSM-III-defined depressive disorder. The cut-off was chosen by Burnam et al. after multiple empirical analyses suggested that it represented a clinically sensible balance between sensitivity and specificity.

\section{Daily dietary intake}

Dietary intake in this study was assessed by 3-day food record or 24-hour recall, and the intake of eight macronutrients (total energy, carbohydrate, total fat, protein, total fibre, saturated fat, simple sugars and long-chain $n-3$ polyunsaturated fatty acids) in the diet was calculated. Every effort was taken to collect reliable dietary data, which included provision of written material instructing participants in keeping a food record, a sample demonstration day of recorded food intake, and a review of the study-specific food record booklet. The trained study staff instructed the participants on how to keep accurate diet records. Participants were given a food scale (Sunbeam Corporation) and a ruler to accurately measure portion sizes. The NFHL study dietitian checked the diet records with the participants for completion and accuracy. If the participant failed to complete the 3-day food record, a 24-hour recall was obtained. Ninety per cent of the whole cohort provided a 3-day record. The food records were analysed by using the Nutrition Data System for Research software, version 4 (Nutrition Coordinating Center, University of Minnesota). A specially trained coder entered the data from the diet records into the database. The complete dietary analysis contains 92 nutrients, but this study used data on eight macronutrients as detailed above.

\section{Symptom score}

The components of symptom score included the following 13 items: headaches that are new, severe or persistent; fevers or night sweats or chills; pain in mouth gums or lips; white patches in mouth; painful rashes or sores on skin, around anus or vagina/penis; nausea or loss of appetite; trouble with eyes; a sinus infection pain or discharge; pain numbness or tingling in hands or feet; persistent coughing or difficulty in breathing for more than one week; vomiting; pain discomfort in the stomach or abdomen; diarrhoea or loose watery stools. Those who 
had experienced any of the above symptoms were asked to assess the severity of each symptom, expressed as 'How much did the symptom interfere with your normal activities?' Response options had five levels ranging from 'not at all' to 'extremely'. Not at all was coded as zero. An aggregate symptom score was the sum of the severity of all symptoms, on a scale from 0 (no symptoms) to 100 (maximum symptom severity). This approach to symptom assessment closely parallels that taken in the HIV Costs and Services Utilization Study (HCSUS) ${ }^{33}$.

\section{Laboratory tests}

CD4 count was determined by flow cytometry. HIV RNA was determined using the Roche Amplicor Monitor (Roche Molecular Systems). The lower detection limit was 400 copies per ml. Results are reported as $\log _{10}$ HIV viral load.

\section{Sociodemographics}

The following variables were included in this analysis: education (low, $\leq$ high school; middle, some college or technical education; high, college and graduate programme), race (African American, White, Hispanic/Latino and others $)$ and personal annual income $(<\$ 10000$, $\$ 10000-\$ 50000,>\$ 50000)$.

\section{Analyses \\ Creation of depressed and non-depressed analytic groups}

NFHL participants who had at least four study visits were considered for this analysis. The 'depressed group' were those participants who had two consecutive visits on which the screening questionnaire indicated no depression followed by two consecutive visits for which the screening questionnaire indicated depression. We required two consecutive visits because the depression measurement instrument is a screener, not a diagnostic instrument. Requiring two consecutive visits increases the chance that those who screened positive had major depression. The total time between the first and the fourth visit ranged from 18 to 24 months. Thus, these were participants who developed depression while being followed in NFHL. The 'non-depressed group' had four consecutive visits on which they were not depressed. For the non-depressed group, these were their first four visits in the NFHL study. During the entire study period patients continued to join the cohort, so these first four visits occurred at a variety of different calendar times, ranging from 1995 to 2003. Using this approach, there were 90 participants in the depressed group and 152 in the nondepressed group.

\section{Descriptive statistics by depression status}

To evaluate baseline differences between those who became depressed and those who did not become depressed, we compared baseline sociodemographic, clinical and nutritional characteristics of the two groups using the $\chi^{2}$ statistic for categorical variables, the $t$-test for normally distributed continuous variables and the Mann-Whitney $U$-test for non-normally distributed continuous variables. The difference in macronutrient intake across groups at baseline was compared separately for men and women. The median (interquartile range) values of macronutrients intake are reported since the macronutrient intakes were not normally distributed. We also examined changes (the difference between values at visit 4 and visit 1) in viral load, CD 4 count, body mass index (BMI) and symptom score for depressed and nondepressed participants using the Wilcoxon signed rank test for related samples.

\section{Univariate and multivariate analyses}

In univariate analyses, for each macronutrient, we calculated the change in intake between visit 4 and visit 1 (a negative value meaning a decrease over time). We did not evaluate the visit just prior to (second visit) and just after (third visit) becoming depressed because we thought that dietary habits might still be in transition. In a separate model for each macronutrient, we calculated the association between developing depression or not (independent variable) and change in macronutrient intake using linear regression analysis. We first performed these models unadjusted for potential confounders. Next, in multivariate models, we tested the association between depression and change in each macronutrient intake (dependent variable) adjusted for confounding using multiple regression analysis.

The potential confounders were baseline values of age, gender, education, race, personal income, BMI, aggregate symptom score, $\log _{10}$ viral load and CD4 count. To determine which variables to include as confounders in each model, we evaluated the association between each potential confounder with the change in each macronutrient intake using Spearman's correlation test for continuous variables, the Mann-Whitney $U$-test for dichotomous variables and the Kruskal-Wallis test for variables with more than two levels. We used methods described by Rothman and Greenland to test for confounding ${ }^{34,35}$. Variables that were associated with a change in macronutrient intake at $P<0.2$ on the univariate analysis were entered into the multivariate models. They remained in the final model if they changed the $\beta$ coefficient for depression by more than $10 \%$ when they were removed. Each model was also adjusted for the baseline value of each macronutrient intake. For multivariate comparisons, we included only participants with complete data on all covariates. We examined for influential observations using Cook's distance and centred leverage values. All statistical analyses were performed using SPSS for Windows 11.5 (SPSS Inc.). Significance was defined as a two-tailed $P$-value equal to or less than 0.05 . 


\section{Results}

\section{Participant characteristics}

Of the 242 participants who screened negative for depression on their first two study visits, 37\% (90/242) screened positive for depression at visits 3 and 4 (Table 1). Those in the depressed and non-depressed groups were similar in age and BMI at baseline. Compared with non-depressed participants, those who developed depression were significantly more likely to be women (37.9 vs. 20.1\%, $P=0.003$ ), less educated (23.3 vs. $45.5 \%$ college graduates, $P=0.008$ ), poorer (54.4 vs. $36.4 \%$ with annual income $<\$ 10000, P=0.008)$ and had a higher symptom score ( 15 vs. $9, P=0.007$ ). Those who developed depression had higher median CD4 cell counts than the non-depressed group at baseline ( 470 vs. 340 per $\left.\mathrm{mm}^{3}, P=0.03\right)$.

\section{Baseline dietary quality}

At baseline, there were no differences between depressed and non-depressed participants in total daily energy intake or in any component of intake (Table 2).

\section{Changes in key clinical variables between visit 1 and visit 4}

The median levels of $\log _{10}$ viral load (3.0 vs. 3.0 copies per $\mathrm{ml}, P=1.0$, Table 3 ) and CD 4 count ( 470 vs. 440 per $\left.\mathrm{mm}^{3}, P=0.9\right)$ were similar at the first and fourth visit in those who became depressed, whereas there was a significant decrease in viral load (2.3 vs. 2.5 copies per ml, $P=0.002$ ) and a significant increase in CD 4 count (330 vs. 437 per $\mathrm{mm}^{3}, P<0.001$ ) in non-depressed participants. There was a significant increase in the symptom score (15 vs. $18, P=0.008$ ) among those who became depressed, but no change ( 9 vs. $10, P=0.1$ ) in non-depressed participants. The data also showed a trend towards a decrease in BMI (25 vs. $24 \mathrm{~kg} \mathrm{~m}^{-2}, P=0.06$ ) among those who developed depression during the study period.

\section{Multivariate analysis of changes in macronutrient intake}

For each macronutrient, the difference in the change in that nutrient intake in the depressed vs. the non-depressed group, adjusted for confounding and baseline intake of that macronutrient, is shown in Table 4. Compared

Table 1 Baseline characteristics

\begin{tabular}{|c|c|c|c|}
\hline \multirow[b]{2}{*}{ Variable } & \multicolumn{2}{|c|}{ Developed depression } & \multirow[b]{2}{*}{$P$-value } \\
\hline & Yes $(n=90)$ & No $(n=152)$ & \\
\hline \multicolumn{4}{|l|}{ Sociodemographic characteristics } \\
\hline Age (years), mean (SD) & $42.1(7.0)$ & $41.9(8.6)$ & 0.9 \\
\hline Female, $n(\%)$ & $34(37.9)$ & $31(20.1)$ & 0.003 \\
\hline \multicolumn{4}{|l|}{ Race, $n(\%)$} \\
\hline African American & $28(31.1)$ & $37(24.3)$ & 0.36 \\
\hline Hispanic/Latino & $7(7.8)$ & $7(4.6)$ & \\
\hline White & $52(57.8)$ & $99(65.1)$ & \\
\hline Others & $3(3.3)$ & $9(5.9)$ & \\
\hline \multicolumn{4}{|l|}{ Education, $n(\%)$} \\
\hline High school & $43(47.8)$ & $48(31.6)$ & 0.002 \\
\hline Trade/technical/some college & $26(28.9)$ & $35(23.5)$ & \\
\hline College/graduate & $21(23.3)$ & $69(45.4)$ & \\
\hline \multicolumn{4}{|l|}{ Personal annual income (\$), $n(\%)$} \\
\hline$<10000$ & $49(54.4)$ & $55(36.4)$ & 0.008 \\
\hline $10000-50000$ & $38(42.2)$ & $79(52.3)$ & \\
\hline$>50000$ & $3(3.4)$ & $18(11.3)$ & \\
\hline \multicolumn{4}{|l|}{ Clinical characteristics } \\
\hline $\mathrm{CD}^{+}$cell count $\left(\right.$per $\mathrm{mm}^{3}$ ), median (IQR) & $470(234,643)$ & $340(189,550)$ & 0.03 \\
\hline HIV load $\left(\log _{10}\right.$ copies per ml), median (IQR) & $3.1(2.3,4.1)$ & $3.3(2.3,4.5)$ & 0.1 \\
\hline Symptom score, median (IQR) & $15(7.7,26.3)$ & $9(5,20)$ & 0.007 \\
\hline \multicolumn{4}{|l|}{$\mathrm{BMI}\left(\mathrm{kg} \mathrm{m}^{-2}\right), n(\%)$} \\
\hline \multicolumn{4}{|l|}{ Men } \\
\hline$<19$ & $3(5.4)$ & $6(5)$ & 1.0 \\
\hline $19-24$ & $26(46.4)$ & $57(47.9)$ & \\
\hline $25-30$ & $22(39.3)$ & 46 (38.7) & \\
\hline$>30$ & $5(8.9)$ & $10(8.4)$ & \\
\hline \multicolumn{4}{|l|}{ Women } \\
\hline$<19$ & $1(2.9)$ & $0(0)$ & 0.7 \\
\hline $19-24$ & $11(32.4)$ & $13(41.9)$ & \\
\hline $25-30$ & $12(35.3)$ & $10(32.3)$ & \\
\hline$>30$ & $10(29.4)$ & $8(25.8)$ & \\
\hline
\end{tabular}

SD - standard deviation; IQR - interquartile range; BMI - body mass index. 
Table 2 Baseline daily dietary intake comparisons in depressed and non-depressed group

\begin{tabular}{|c|c|c|c|}
\hline \multirow[b]{2}{*}{ Macronutrient } & \multicolumn{2}{|c|}{ Median baseline intake (IQR) } & \multirow[b]{2}{*}{$P$-value } \\
\hline & Depression & Controls & \\
\hline \multicolumn{4}{|c|}{ Total energy (kcal) } \\
\hline Men & $2777(2303,3641)$ & $2933(2424,3420)$ & 0.6 \\
\hline Women & $2027(1551,2499)$ & $2190(1420,2836)$ & 0.8 \\
\hline \multicolumn{4}{|l|}{ Protein $(\mathrm{g})$} \\
\hline Men & $113(90,126)$ & $114(88,136)$ & 0.6 \\
\hline Women & $67(55,92)$ & $85(62,110)$ & 0.2 \\
\hline \multicolumn{4}{|l|}{ Total fat $(\mathrm{g})$} \\
\hline Men & $113(86,138)$ & $111(87,140)$ & 0.9 \\
\hline Women & $76(60,101)$ & $78(55,119)$ & 0.8 \\
\hline \multicolumn{4}{|c|}{ Carbohydrate (g) } \\
\hline Men & $348(271,467)$ & $354(264,444)$ & 1.0 \\
\hline Women & $250(193,376)$ & $306(189,365)$ & 0.9 \\
\hline \multicolumn{4}{|l|}{ Total fibre (g) } \\
\hline Men & $18.5(14.0,24.0)$ & $19.4(13.6,25.6)$ & 0.9 \\
\hline Women & $13(9.0,15.3)$ & $15.9(9.4,22.7)$ & 0.08 \\
\hline \multicolumn{4}{|c|}{ Saturated fat $(\mathrm{g})$} \\
\hline Men & $43(31,49)$ & $39(30,49)$ & 0.7 \\
\hline Women & $28(24,35)$ & $29(19,42)$ & 0.9 \\
\hline \multicolumn{4}{|c|}{ Simple sugars (g) } \\
\hline Men & $169(137,229)$ & $159(118,227)$ & 0.6 \\
\hline Women & $126(85,213)$ & $138(90,198)$ & 0.7 \\
\hline \multicolumn{4}{|c|}{$n-3$ fatty acids $(\mathrm{g})$} \\
\hline Men & $0.17(0.07,0.44)$ & $0.11(0.05,0.34)$ & 0.3 \\
\hline Women & $0.08(0.04,0.21)$ & $0.12(0.05,0.37)$ & 0.2 \\
\hline
\end{tabular}

Table 3 Visit 1 to visit 4 changes in clinical characteristics, median (IQR)

\begin{tabular}{|c|c|c|c|c|c|c|}
\hline \multirow[b]{2}{*}{ Variable } & \multicolumn{3}{|c|}{ Depression } & \multicolumn{3}{|c|}{ Controls } \\
\hline & Visit 1 & Visit 4 & $P$-value & Visit 1 & Visit 4 & $P$-value \\
\hline Viral load $\left(\log _{10}\right.$ copies per $\left.\mathrm{ml}^{3}\right)$ & $3.0(2.3,4.1)$ & $3.0(2.3,4.1)$ & 1.0 & $3.3(2.3,4.5)$ & $2.3(2.3,3.8)$ & 0.002 \\
\hline CD4 cell count (per mm³) & $470(242,643)$ & $440(259,605)$ & 0.9 & $330(179,530)$ & $437(246,625)$ & $<0.001$ \\
\hline Symptom score & $15(8,28)$ & $18(9,31)$ & 0.008 & $9(5,20)$ & $10(5,17)$ & 0.1 \\
\hline BMI $\left(\mathrm{kg} \mathrm{m}^{-2}\right)$ & $25(23,28)$ & $24(22,28)$ & 0.06 & $24(22,27)$ & $25(22,28)$ & 0.3 \\
\hline
\end{tabular}

IQR - interquartile range; $\mathrm{BMI}$ - body mass index.

Table 4 Individual multivariate models of changes (visit 1 to visit 4) in daily nutrient intake

\begin{tabular}{lcll}
\hline Variable & Change in intake $(95 \% \mathrm{Cl})$ & $P$-value & \multicolumn{1}{c}{ Covariates } \\
\hline Total energy (kcal) & $-341(-585,-96)$ & 0.006 & Education, viral load, symptom score, baseline energy intake \\
Protein $(\mathrm{g})$ & $-12.3(-22.6,-2.0)$ & 0.02 & Income, symptom score, baseline protein intake \\
Total fat $(\mathrm{g})$ & $-18.5(-32.1,-4.9)$ & 0.008 & Education, viral load, baseline total fat \\
Carbohydrate $(\mathrm{g})$ & $-36.8(-66.5,-6.9)$ & 0.02 & Symptom score, baseline carbohydrate intake \\
Total fibre $(\mathrm{g})$ & $-4.3(-6.7,-1.8)$ & 0.001 & Baseline fibre \\
Saturated fat $(\mathrm{g})$ & $-6.7(-11.9,-1.4)$ & 0.01 & Education, baseline saturated fat \\
Simple sugars $(\mathrm{g})$ & $-16.5(-37.0,4.0)$ & 0.15 & CD4 count, baseline sugar intake \\
$n-3$ fatty acids $(\mathrm{g})$ & $0.03(-0.16,0.09)$ & 0.45 & Race, baseline $n-3$ fatty acids intake \\
BMI (kg m $\left.{ }^{-2}\right)$ & $0.29(-0.35,0.93)$ & 0.37 & Sex, race, viral load, education \\
\hline
\end{tabular}

$\mathrm{Cl}$ - confidence interval; BMI - body mass index.

with non-depressed participants, depressed participants had significantly greater decreases in the following daily intakes: total energy $(-341 \mathrm{kcal}, \quad P=0.006)$, protein $(-12.3 \mathrm{~g}, P=0.02)$, total fat $(-18.5 \mathrm{~g}, P=0.008)$, carbohydrate $(-36.8 \mathrm{~g}, P=0.02)$, total fibre $(-4.3 \mathrm{~g}, P=0.001)$ and saturated fat $(-6.7 \mathrm{~g}, P=0.01)$. There were no differences in simple sugars or long-chain $n-3$ fatty acids. There was a non-significant trend toward reduced BMI among depressed patients $\left(-0.29 \mathrm{~kg} \mathrm{~m}^{-2}, P=0.37\right)$.

\section{Discussion}

We found that total energy intake, and intake of six of eight dietary components, fell in patients who developed depression. The patients we studied who developed depression did not appear to change the composition of their diet, but they did take in significantly fewer total calories. That is, they seemed to eat less of everything. Of particular note, our findings did not suggest any increase 
in carbohydrate intake or sugar intake associated with depression, as reported by Christensen and Somers in their study ${ }^{11}$. While decreased intake of total and saturated fat may be beneficial, these changes were not accompanied by increases in protein or fibre, and so overall dietary composition did not appear to change. Interestingly, energy intake did not decrease so much that there was a significant reduction in BMI. It is unclear from our analysis why BMI did not fall more than it did. One possibility is that these depressed patients exercised less and in general expended less energy, which would reduce the impact of reduced energy intake on BMI. However, we did not have quantitative data on exercise or physical activity that we could use in this analysis. HIV clinicians should be aware that their patients who develop depression may have decreased total energy intake, and watch for weight loss.

There are several study limitations. First, determining a clear cause-and-effect relationship between depression and dietary intake for patients with a complex disease such as HIV is difficult. The particular longitudinal design we used has important strengths, but also some weaknesses. Because we examined changes in an individual's dietary intake before and after the development of depression, many potentially confounding factors were effectively held constant by the study design, such as race, attitudes towards food and eating, and beliefs about mental health diagnoses and treatments. This important feature of the longitudinal design notwithstanding, some important factors can change for individuals over time, such as the manifestations of co-morbid diseases. Participants who developed depression had more symptoms of associated medical conditions and, in contrast to the control group, there was no improvement in their disease status as measured by CD4 count and viral load during the study period, which in theory might contribute to the development of depression. However, we controlled for this and other potential confounders in our multivariate analyses. A minor weakness is that because we collected data every 6 months, we do not have an exact date for either the onset of depression or the changes in intake that we observed. Thus, it is theoretically possible that these dietary changes caused participants to develop depression, and not the reverse, although we think that this is unlikely.

Second, the validity of self-reported dietary data, particularly data from less-educated and obese individuals, has been controversial ${ }^{36,37}$. Nevertheless, diet records are the most accurate method of dietary analysis for studies that include many subjects of ethnic minorities. A study has been published showing good correlation between dietary intake inadequacy and the presence of hunger in this cohort that supports the general validity of the dietary record data for this $\operatorname{cohort}^{38}$. Third, we used a short screening instrument to detect depression (the only short depression screener that had been carefully validated in
1995 when our study began). Screening instruments, designed to be sensitive, almost invariably overestimate disease rates. However, the scale used in this study has a reasonable sensitivity for recent ( 6 months) and current depression (74-89\%) and quite a high specificity (95\%) at the cut-off we used. Furthermore, because we required that participants had two consecutive visits without depression, and then two consecutive visits with depression, we believe that we have reduced the false positive rate significantly. Fourth, our findings might not be generalisable to other populations with HIV with different characteristics, or to those who do not have HIV. Finally, while we were interested in macronutrient intake, further studies that focus on the relationship between micronutrient intake and depression in persons with HIV would be valuable.

In conclusion, we found that patients who developed depression also reported reduced total energy intake and reductions in intake of six of eight dietary components. To our knowledge, this is the first time that changes in dietary intake have been associated with depression in persons with HIV. Depression has been associated with increased mortality in a number of studies ${ }^{39-42}$, but the mechanisms that might explain the association are not known. Our findings suggest that poor nutrition should be explored as a potential contributing factor.

These finding have two main implications for physicians. First, even though the reductions in energy intake that we show were not significantly associated with decreases in BMI, our findings should be a reminder to clinicians to include depression in the differential diagnosis for persons with HIV-related weight loss. Second, while it is not practical for HIV clinicians to monitor energy intake of patients with depression, they should carefully monitor depressed patients' weight, and provide adequate education and treatment when weight loss is discovered.

\section{Acknowledgements}

Sources of funding: This work was supported by NIDDK (1P01DK45734-06), the General Research Center of the Tufts-New England Medical Center (M01RR00054), and the Lifespan/Tufts/Brown Center for AIDS Research (P30A142853).

Conflict of interest declaration: None.

Authorship responsibilities: D.J., C.W., K.H., T.A.K. and I.B.W. were responsible for data collection. All authors contributed to data analysis and preparation of the manuscript.

\section{References}

1 Wanke CA, Silva M, Knox TA, Forrester J, Spiegelman D, Gorbach SL. Weight loss and wasting remain common complications in individuals infected with human immunodeficiency virus in the era of highly active antiretroviral therapy. Clinical Infectious Diseases 2000; 31(3): 803-5. 
2 Tang AM. Weight loss, wasting, and survival in HIV-positive patients: current strategies. The AIDS Reader 2003; 13(12 Suppl.): S23-7.

3 Tang AM, Forrester J, Spiegelman D, Knox TA, Tchetgen E, Gorbach SL. Weight loss and survival in HIV-positive patients in the era of highly active antiretroviral therapy. Journal of Acquired Immune Deficiency Syndromes 2002; 31(2): 230-6.

4 Arnalich F, Martinez P, Hernanz A, Gonzalez J, Plaza MA, Montiel C, et al. Altered concentrations of appetite regulators may contribute to the development and maintenance of HIV-associated wasting. AIDS 1997; 11(9): 1129-34.

5 Tang AM, Jacobson DL, Spiegelman D, Knox TA, Wanke C. Increasing risk of $5 \%$ or greater unintentional weight loss in a cohort of HIV-infected patients, 1995 to 2003. Journal of Acquired Immune Deficiency Syndromes 2005; 40(1): 70-6.

6 Melchior JC, Niyongabo T, Henzel D, Durack-Bown I, Henri SC, Boulier A. Malnutrition and wasting, immunodepression, and chronic inflammation as independent predictors of survival in HIV-infected patients. Nutrition 1999; 15(11-12): 865-9.

7 Shevitz AH, Knox TA, Spiegelman D, Roubenoff R, Gorbach SL, Skolnik PR. Elevated resting energy expenditure among HIV-seropositive persons receiving highly-active antiretroviral therapy. AIDS 1999; 13(11): 1351-7.

8 Jacobson DL, Bica I, Knox TA, Wanke C, Tchetgen E, Spiegelman D, et al. Difficulty swallowing and lack of receipt of highly active antiretroviral therapy predict acute weight loss in human immunodeficiency virus disease. Clinical Infectious Diseases 2003; 37(10): 1349-56.

9 Carbonnel F, Beaugerie L, Abou RA, D'Almagne $\mathrm{H}$, Rozenbaum W, Le QY, et al. Macronutrient intake and malabsorption in HIV infection: a comparison with other malabsorptive states. Gut 1997; 41(6): 805-10.

10 Cruess DG, Evans DL, Repetto MJ, Gettes D, Douglas SD, Petitto JM. Prevalence, diagnosis, and pharmacological treatment of mood disorders in HIV disease. Biological Psychiatry 2003; 54(3): 307-16.

11 Christensen L, Somers S. Comparison of nutrient intake among depressed and nondepressed individuals. International Journal of Eating Disorders 1996; 20(1): 105-9.

12 Edwards R, Peet M, Shay J, Horrobin D. Omega-3 polyunsaturated fatty acid levels in the diet and in red blood cell membranes of depressed patients. Journal of Affective Disorders 1998; 48(2-3): 149-55.

13 Peet M. International variations in the outcome of schizophrenia and the prevalence of depression in relation to national dietary practices: an ecological analysis. British Journal of Psychiatry 2004; 184: 404-8.

14 Morris MS, Fava M, Jacques PF, Selhub J, Rosenberg IH. Depression and folate status in the US population. Psychotherapy and Psychosomatics 2003; 72(2): 80-7.

15 Rosche J, Uhlmann C, Froscher W. Low serum folate levels as a risk factor for depressive mood in patients with chronic epilepsy. Journal of Neuropsychiatry and Clinical Neurosciences 2003; 15(1): 64-6.

16 Bottiglieri T, Hyland K, Laundy M, Godfrey P, Carney MW, Toone BK, et al. Folate deficiency, biopterin and monoamine metabolism in depression. Psychological Medicine 1992; 22(4): 871-6.

17 Lindenbaum J, Healton EB, Savage DG, Brust JC, Garrett TJ, Podell ER, et al. Neuropsychiatric disorders caused by cobalamin deficiency in the absence of anemia or macrocytosis. New England Journal of Medicine 1988; 318(26): $1720-8$.

18 Burnam MA, Wells KB, Leake B, Landsverk J. Development of a brief screening instrument for detecting depressive disorders. Medical Care 1988; 26(8): 775-89.
19 Stewart AL, Ware JE, eds. Measuring Function and WellBeing: The Medical Outcomes Study Approach. Durham, NC: Duke University Press, 1992.

20 Radloff LN. The CES-D scale: a self-report depression scale for research in the general population. Applied Psychological Measurement 1977; 1: 385.

21 Weissman MM, Sholomskas D, Pottenger M, Prusoff BA, Locke BZ. Assessing depressive symptoms in five psychiatric populations: a validation study. American Journal of Epidemiology 1977; 106(3): 203-14.

22 Myers JK, Weissman MM. Use of a self-report symptom scale to detect depression in a community sample. American Journal of Psychiatry 1980; 137(9): 1081-4.

23 Weissman MM, Pilowsky DJ, Wickramaratne PJ, Talati A, Wisniewski SR, Fava M, et al. Remissions in maternal depression and child psychopathology: a STAR*D-child report. JAMA: Journal of the American Medical Association 2006; 295(12): 1389-98.

24 Robins LN, Helzer JE, Ratcliff KS, Seyfried W. Validity of the diagnostic interview schedule, version II: DSM-III diagnoses. Psychological Medicine 1982; 12(4): 855-70.

25 Robins LN, Helzer JE, Croughan J, Ratcliff KS. National Institute of Mental Health Diagnostic Interview Schedule. Its history, characteristics, and validity. Archives of General Psychiatry 1981; 38(4): 381-9.

26 Sherman AM. Social relations and depressive symptoms in older adults with knee osteoarthritis. Social Science \& Medicine 2003; 56(2): 247-57.

27 Ahluwalia JS, Richter K, Mayo MS, Ahluwalia HK, Choi WS, Schmelzle KH, et al. African American smokers interested and eligible for a smoking cessation clinical trial: predictors of not returning for randomization. Annals of Epidemiology 2002; 12(3): 206-12.

28 Hlatky MA, Boothroyd D, Vittinghoff E, Sharp P, Whooley MA. Quality-of-life and depressive symptoms in postmenopausal women after receiving hormone therapy: results from the Heart and Estrogen/Progestin Replacement Study (HERS) trial. JAMA: Journal of the American Medical Association 2002; 287(5): 591-7.

29 Katz DA, McHorney CA. The relationship between insomnia and health-related quality of life in patients with chronic illness. Journal of Family Practice 2002; 51(3): 229-35.

30 Foy CG, Wickley KL, Adair N, Lang W, Miller ME, Rejeski WJ, et al. The Reconditioning Exercise and Chronic Obstructive Pulmonary Disease Trial II (REACT II): rationale and study design for a clinical trial of physical activity among individuals with chronic obstructive pulmonary disease. Contemporary Clinical Trials 2006; 27(2): 135-46.

31 Woods NF, LaCroix AZ, Gray SL, Aragaki A, Cochrane BB, Brunner RL, et al. Frailty: emergence and consequences in women aged 65 and older in the Women's Health Initiative Observational Study. Journal of the American Geriatrics Society 2005; 53(8): 1321-30.

32 Sivarajan Froelicher ES, Miller NH, Christopherson DJ, Martin K, Parker KM, Amonetti M, et al. High rates of sustained smoking cessation in women hospitalized with cardiovascular disease: the Women's Initiative for Nonsmoking (WINS). Circulation 2004; 109(5): 587-93.

33 Hays RD, Spritzer KL, McCaffrey D, Cleary PD, Collins R, Sherbourne C, et al. The HIV Cost and Services Utilization Study (HCSUS) Measures of Health-Related Quality of Life. DRU-1997-AHCPR. Santa Monica, CA: RAND Corporation, 1998.

34 Rothman K, Greenland S. Modern Epidemiology. Philadelphia, PA: Lippincott Williams \& Wilkins, 1998.

35 Robins JM, Greenland S. The role of model selection in causal inference from nonexperimental data. American Journal of Epidemiology 1986; 123(3): 392-402.

36 Azizi F, Esmaillzadeh A, Mirmiran P. Correlates of underand over-reporting of energy intake in Tehranians: body 
mass index and lifestyle-related factors. Asia Pacific Journal of Clinical Nutrition 2005; 14(1): 54-9.

37 Rennie KL, Jebb SA, Wright A, Coward WA. Secular trends in under-reporting in young people. British Journal of Nutrition 2005; 93(2): 241-7.

38 Kim J. The Correlates of Hunger and Reduced Dietary Intake in a Cohort of HIV-positive Adults of the Boston Area: A Cross Sectional Study with Analysis of Data Quality and Post-Recruitment Retention Rates. Boston, MA: Harvard School of Public Health, 2001.

39 Ferrando S, Evans S, Goggin K, Sewell M, Fishman B, Rabkin J. Fatigue in HIV illness: relationship to depression, physical limitations, and disability. Psychosomatic Medicine 1998; 60(6): 759-64.
40 Ickovics JR, Hamburger ME, Vlahov D, Schoenbaum EE, Schuman P, Boland RJ, et al. Mortality, CD4 cell count decline, and depressive symptoms among HIV-seropositive women: longitudinal analysis from the HIV Epidemiology Research Study. JAMA: Journal of the American Medical Association 2001; 285(11): 1466-74.

41 Page-Shafer K, Delorenze GN, Satariano WA, Winkelstein Jr W. Comorbidity and survival in HIV-infected men in the San Francisco Men's Health Survey. Annals of Epidemiology 1996; 6(5): 420-30.

42 Mayne TJ, Vittinghoff E, Chesney MA, Barrett DC, Coates TJ. Depressive affect and survival among gay and bisexual men infected with HIV. Archives of Internal Medicine 1996; 156(19): 2233-8.

\section{Appendix -Depression Screener Items}

1. In the past year, have you had 2 weeks or more during which you felt sad, blue, or depressed; or when you lost all interest or pleasure in things that you usually cared about or enjoyed? (Yes/No)

2. Have you had 2 years or more in your life when you felt depressed or sad most days, even if you felt okay sometimes? (Yes/No) If no, go to question 3.

2a. Have you felt depressed or sad much of the time in the past year? (Yes/No)

3. For each statement below, mark one circle that best describes how much of the time you felt or behaved this way during the past week. Response options are:

0: Rarely or none of the time (less than one day)

1: Some or a little of the time (1-2 days)

2: Occasionally or moderate amount of the time (3-4 days)

3: Most or all of the time ( $5-7$ days)

During the past week:

a. I felt depressed

b. I had crying spells

c. I felt sad

d. I enjoyed life

e. My sleep was restless

f. I felt that people disliked me 